\title{
Die Bescherung
}

\section{E. Taverna}

Kleine Geschenke erhöhen die Freundschaft, sagt man. Sie verstärken die Bindung unter Liebenden und sichern die der Angestellten und Kunden. Manche Geschenke bringen Unheil, wenn sie bei einer Trennung zum Streitobjekt geraten oder wenn sie unerwartet ins Verderben führen. Manche Gaben wirken wie der Doppelsinn der sprachlichen Herkunft, als das englische «gift». Der Pelzmantel für die Frau Gemahlin wird dem Politiker zum Stolperstein, wie Spenden-, Schmier- und andere Gelder, oder Affären mit Tänzerinnen. Die Griechenklassiker sind voll von solchen Geschichten, nur sind

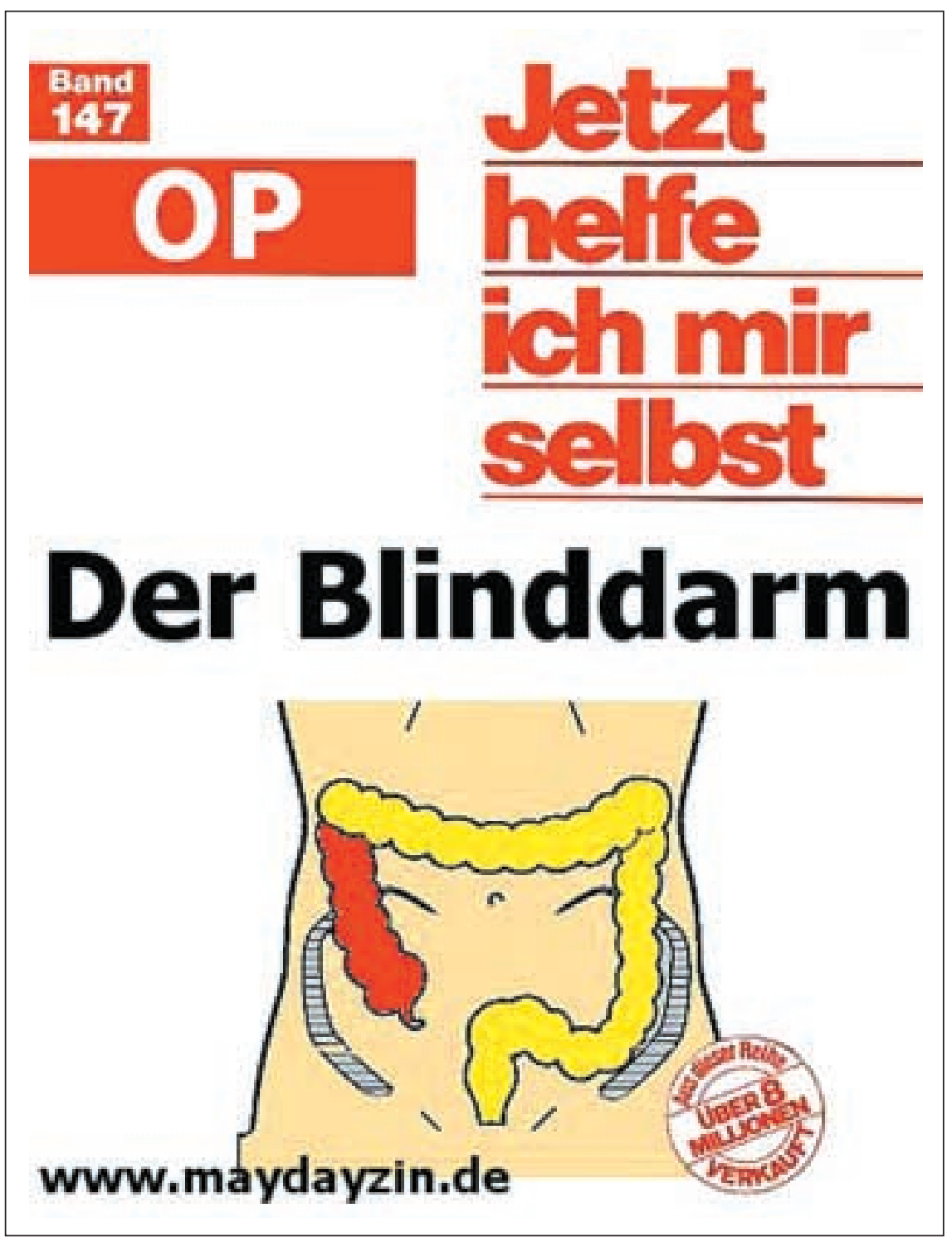

diese üppiger und tragischer als der Boulevardklatsch über strauchelnde Ständeräte und Diplomaten. Zum Beispiel die von Nessos Gruselgewand. Das mit seinem Blut getränkte Hemd vermachte der sterbende Kentaur der Frau, die er eben hatte vergewaltigen wollen. Einen mächtigen Liebeszauber versprach er ihr, der jeden Träger für immer an sie binden werde. Doch als sie es ihrem Liebhaber Herakles sandte, starb dieser am Gift der späten Rache. Doch die berühmteste aller Geschichten ist die von Pandora. Sie ist zum Sinnbild aller ähnlich zweideutigen Geschenke geworden und gehört schon darum zum Restbestand abendländischer Bildungstradition.

Pandora war die erste Frau, ein Rachegeschenk von Zeus an eine damals noch reine Männergesellschaft, die sich gegen seinen Willen zu Menschen zivilisierte. Der Göttervater liess eine Barbie-Puppe herstellen, ein künstliches Wesen, den Göttinnen nachgeformt, «mit einer hündischen Seele und einer diebischen Natur.» Sie ist ein Archetyp von Weib, verführerisch schön und gleichzeitig gefrässig und fruchtbar. Sie ist der Bauch, der alles verschlingt, was der Ehemann geerntet hat, und der Bauch, der die Nachkommen in die Welt bringt. Sie vereinigt das Göttliche mit dem Menschlichen, und sie öffnet den Tonkrug, auch der ein Geschenk, aus dem alle Übel, bis auf die Hoffnung, in die Welt entweichen. Die Tat hat Folgen bis zum heutigen Tag, und immer wieder sind es Geschenke, die den Lauf der Geschichte ändern.

Der Olymp hat heute andere Namen und andere Konzepte. Lange hat er die Mediziner mit Geschenken verwöhnt. Doch jetzt ist die Zeit reif, auf dass er sein Füllhorn über das ganze Volk ergiesse und es aus der langen Abhängigkeit von sterblichen Halbgöttern befreie. Papacheck $\mathrm{GmbH}$ wirbt für den Vaterschaftstest auf die Schnelle. Die Industrie gibt dem Heer der Misstrauischen und Frustrierten die ersehnte Waffe in die Hand. Kein Gerichtsverfahren, keine Vaterschaftsklage, es genügen ein Internetformular und ein diskretes Paket für vorläufig noch 500 Franken. Zwei Wattestäbchen in steriler Verpackung, etwas Speichel und ab die Post. Wenn nötig genügt auch ein benutztes Papiertaschentuch, Spermaflecken oder ein Zigarettenfilter. Es geht auch ohne Kenntnis der 
Mutter oder Testperson, mit 99,9\% Sicherheit, und für einen Aufpreis, innerhalb von drei Tagen. Leider werden die anonymen Hausteste vom Gericht nicht anerkannt. Doch «der Kampf gegen Matriarchat und Staat» geht weiter, ob nun die SDK Richtlinien im Sinne von «Lesen Sie die Packungsbeilage und fragen Sie eine Fachperson» erlässt oder nicht.

Doch Pandoras Tonkrug hat noch viele weitere Überraschungen auf Lager. Wie wäre es mit dem Weihnachtskit der Firma Quidel aus Kalifornien? Verlassen Sie sich nicht auf die Grippeimpfung, wenn Sie sich nicht selber gepikst haben. Machen Sie den Quick-Influenzatest, Resultat in 10 Minuten. Billiger im Kombipack mit dem In-vitro-Diagnostika-Set für Chlamydien, Helicobacter pylori, Streptokokken und hCG. Wer schon alles hat, lässt sich vielleicht mit dem pH-Test Lolli-Doc überraschen, dem Lutscher, der das Kariesrisiko misst oder mit dem pH am Muttermund das Risiko einer Frühgeburt. Zur Gewichts- und Blutdruckkontrolle im Klo mit Harn- und Stuhltest made in Japan gehören heute der familienfreundliche Drogen- check für die Kinderchen und die Selbstdiagnose Software 2002 «Gehen Sie Ihren Beschwerden auf den Grund.» Fragebogen für den wöchentlichen Neurose- und Depressionsstatus lassen sich bequem ausdrucken und mit Ihrem BurnoutScore und EKG telematisch verarbeiten. Wer es lieber alternativ hat, bestellt sich vom Institut für wissenschaftliche Chirologie die Anleitung für Selbstdiagnose durch Kopflinien, oder für diese Weihnachten vielleicht doch lieber die Vollspektrumlampe für's Immunsystem. Fortgeschrittene haben natürlich bereits die Reife der Selbstbehandlung erreicht. Der Mündige überlegt sich die Anschaffung der «OP-Ausstattung für die Privatgarage» mit dem unentbehrlichen Band 147 «Jetzt helfe ich mir selbst.» Für terminale Absichten verfügen Exit-Mitglieder schon längst über mindestens zwei genaue Anleitungen der Do-it-yourself-Methode.

Irgendwo, zwischen Sozialabbau und Grössenwahn, gedeihen ganz neue, fiese, einträgliche Geschenkideen, wie diese kleine Auswahl zeigt. Quod erat demonstrandum, was zu beweisen war. 